\title{
Prevención y control de la infección ante sujetos sospechosos de infección por el nuevo coronavirus MERS-CoV en Unidades militares
}

\author{
Mayo Montero Mª E. ${ }^{1}$, Cique Moya A. ${ }^{2}$, Cascante Burgos J. ${ }^{3}$, Méndez Montesinos JR. ${ }^{4}$ \\ Sanid. mil. 2015; 71 (3): 196-200; ISSN: 1887-8571
}

\begin{abstract}
RESUMEN
Los primeros casos del nuevo coronavirus MERS-CoV surgieron en Arabia Saudí en el año 2012. Hasta la fecha el virus se ha extendido a países vecinos, notificándose casos importados en Europa, América del Norte, África y Asia. En mayo de 2015 se declara a la OMS el primer caso confirmado por laboratorio de un brote en Corea del Sur, donde se ha producido hasta transmisión cuaternaria. El agente se transmite por vía aérea, por contacto directo con secreciones infectadas y por fómites, presenta una letalidad en torno al 37\%. Por lo que en el manejo de pacientes se adoptarán precauciones estándar, de contacto y de transmisión aérea cuando se apliquen técnicas que generen aerosoles. Debido a la gravedad de la enfermedad y al desconocimiento de los mecanismos de transmisión, resulta prioritario establecer en las unidades militares donde se sospeche la aparición de un caso las medidas de prevención y control de la infección para: detectar rápida y precozmente un caso sospechoso, proteger al personal sanitario, a otros pacientes y al resto del personal, así como implementar las medidas de aislamiento apropiadas.
\end{abstract}

PALABRAS CLAVE: MERS-Cov, Coronavirus, Prevención, Control de la infección, Aislamiento, Equipo de Protección Individual.

Prevention and infection control to suspected cases of infection with the new coronavirus MERS-CoV in military units

SUMMARY: MERs-CoV It was first reported in Saudi Arabia in 2012.To date the virus has spread to several neighboring countries and cases has been detected from travelers with direct or indirect connection with the Middle East in Europe, North America, Africa and Asia. On May 2015, the Republic of Korea notified WHO of the first laboratory-confirmed case of Middle East respiratory syndrome coronavirus (MERS-CoV) and an outbreak with quaternary transmission. The transmission of the virus from person to person is thought to spread from an infected person's respiratory secretions and fomites. Case-fatality ratio reported so far has been around 37\%. It should have standard infection prevention and control practices in place for infectious diseases in general for the management of suspected cases droplet precautions, including eye protection, should be added to the standard precautions when providing care to any patient with symptoms of acute respiratory infection. Due to the severity and unknown transmissions mechanism policies and procedure for rapid screening and assessment of potential MERS-cases should be in place to ensure rapid care of the patient and to minimize the number of contacts among other patients, visitors and health workers.

KEYWORDS: MERS-CoV, Coronavirus, Prevention, Infection control, Isolation, Personal Protective Equipment.

\section{ANTECEDENTES Y SITUACIÓN EPIDEMIOLÓGICA}

En Septiembre de 2012 se identificaron los dos primeros casos de infección por un nuevo virus de la familia Coronaviridae en Arabia Saudí, denominado posteriormente Síndrome Respiratorio de Oriente Medio causado por Coronavirus, MERS-CoV (Middle East Respiratory Syndrome Coronavirus). Investigaciones retrospectivas posteriores identificaron que los primeros casos de infección por MERS-CoV ocurrieron en Jordania en abril de 2012. Hasta el 9 de junio del 2015, la OMS ha comunicado

${ }^{1}$ Cte. Médico. Servicio de Epidemiología e Inteligencia Sanitaria.

${ }^{2}$ Tcol. Veterinario. Servicio de Sanidad Ambiental y NBQ.

${ }^{3}$ Tcol. Médico.

${ }^{4}$ Cor. Médico

Instituto de Medicina Preventiva de la Defensa "Capitán Médico Ramón y Cajal”

Dirección para correspondencia: $\mathrm{M}^{\mathrm{a}}$ Elga Mayo Montero. Instituto de Medicina Preventiva de la Defensa "Capitán Médico Ramón y Cajal". Gta. del Ejército 1. 28047 Madrid. España.

Recibido: 2 de julio de 2015

Aceptado: 10 de julio de 2015
1.250 casos confirmados de infección por MERS- CoV, incluyendo 449 muertes (letalidad 37,2\%) ${ }^{1}$.

Hasta la fecha, todos los casos de MERS-CoV han ocurrido en diez países del Oriente Próximo (Arabia Saudí, Egipto, Irán, Jordania, Kuwait, Líbano, Omán, Qatar, Emiratos Árabes Unidos (EAU) y Yemen). Arabia Saudí acumula el mayor número de casos. Fuera de Oriente Próximo, se han notificado 18 casos importados ( 7 fallecidos) en varios países en viajeros procedentes de la Península Arábiga²:

- Región Africana: Argelia, Túnez y Egipto;

- Norte América: Estados Unidos;

- Región Europea: Francia, Alemania, Grecia, Italia, Reino Unido, Países Bajos y Austria.

- El 20 de mayo, Corea del Sur notificó a la OMS el primer caso confirmado de MERS-CoV en Asia. Hasta el 12 de junio de 2015, la OMS ha notificado 125 casos adicionales confirmados de MERS-CoV (124 en Corea del Sur y 1 en China), incluyendo 10 fallecimientos. Tailandia también ha registrado casos en las últimas semanas. 
Es fundamental garantizar la aplicación efectiva de las medidas de prevención y control de infecciones para conseguir ${ }^{3,4}$ :

- Detectar rápida y precozmente un caso sospechoso.

- Proteger al personal sanitario, a otros pacientes y al resto del personal (familiares).

- Implementar las medidas de cuarentena y aislamiento apropiadas.

\section{PREVENCIÓN Y CONTROL DE LA TRASMISIÓN}

Las medidas propuestas están basadas en las recomendaciones de la OMS y del Comité de Seguridad Sanitaria y el Sistema de Alerta Precoz y Respuesta Rápida de la Unión Europea y del Procedimiento de actuación frente a casos de infección por el nuevo coronavirus (MERS-CoV) (Elaborado por la Ponencia de Alertas de Salud Pública y Planes de Preparación y Respuesta y aprobado por la Comisión de Salud Pública el 11.02.2015) y tienen en cuenta las incertidumbres que actualmente existen en relación al riesgo de transmisión del virus ${ }^{5-6}$. Motivo por el cual están en revisión permanente en función de la evolución y nueva información que se disponga de la infección por el nuevo coronavirus (MERS - CoV).

Los coronavirus se transmiten principalmente por las gotas respiratorias de más de 5 micras y por el contacto directo con las secreciones infectadas. También podrían transmitirse por aerosoles en procedimientos que los produzcan. Estos virus también se han detectado en heces y orina.

Las precauciones adecuadas para el manejo de los pacientes en investigación o confirmados de infección por MERS-CoV incluyen las precauciones estándar, precauciones de contacto y precauciones de transmisión por gotas. Se aplicarán precauciones de transmisión aérea siempre que se apliquen técnicas que generen aerosoles.

Se describen de forma más detallada las recomendaciones mínimas a seguir, que se irán revisando según se disponga de más información sobre la enfermedad y sus mecanismos de transmisión.

\section{Medidas de prevención}

Es importante reducir al mínimo la exposición a cualquier patógeno respiratorio incluyendo MERS-CoV, sobre todo en $\mathrm{ZO}$ donde es fundamental el seguimiento de las siguientes medidas preventivas ${ }^{7-10}$ :

1. Evitar el contacto directo con animales sospechosos responsables de la transmisión primaria (camellos, murcié$\operatorname{lagos} .$.$) .$

- No visitar granjas o lugares con alta concentración de animales, asi como mercados.

- No consumir alimentos procedentes de animales sospechosos por ejemplo carne o leche de camello.

2. Evitar el contacto directo con personas con síntomas indicativos de infección respiratoria (por ejemplo fiebre, tos, secreción nasal, dificultad respiratoria) y tomar acciones preventivas adecuadas (por ejemplo, usar al menos mascarilla quirúrgica). Evitar los servicios de urgencias o lugares con gran aglomeración de personas.

- Restringir al máximo la visita a centros sanitarios u hospitales localizados en las zonas afectadas (se actualizará según la situación epidemiológica) y que no garanticen las condiciones de detección precoz y protección de la transmisión de enfermedades.

3. Asegurar en cualquier circunstancia las normas generales de prevención de enfermedades trasmisibles de este tipo:

- Lavado frecuente de manos con agua y jabón, si no se dispone de jabón la solución hidroalcohólica.

- No tocar la nariz, los ojos ni la boca con las manos, pues son localización del virus.

- Utilizar siempre pañuelos desechables.

- En el primer momento de notar fiebre, tos, dificultad respiratoria o cualquier síntoma respiratorio de gravedad consultar con los servicios sanitarios quienes valoraran el uso de mascarilla.

\section{Medidas de protección}

Estas medidas pretenden evitar la trasmisión de la infección mediante las precauciones estándar, precauciones de contacto y precauciones de transmisión por gotas. Los elementos de estas precauciones estándar se aplicarían a cualquier paciente con infección respiratoria, incluida la causada por MERS-CoV ${ }^{11,12}$ :

1. Todo el personal (sanitario y no sanitario) debe recibir información a acerca de la enfermedad, el mecanismo de transmisión y las medidas de prevención y protección. Se debe prestar atención a:

- la correcta y frecuente higiene de manos

- instrucciones de protección para cubrir la nariz y la boca al toser o estornudar así como de cómo usar mascarillas

- incidir en la adecuada gestión de residuos.

2. El personal sanitario debe detectar de forma rápida y activa a cualquier paciente con Infección Respiratoria Aguda (IRA) que pueda alertar sobre un caso sospechoso de MERS-CoV ante cualquier paciente con sintomatología compatible y manifieste antecedentes de haber estado en las zonas señaladas de riesgo en los 14 días previos al inicio de síntomas o bien hayan estado en contacto con un caso en investigación o confirmado de MERS-CoV.

- En julio de 2015 la recomendación actual se extiende a los siguientes países: Jordania, Arabia Saudí, Qatar, Kuwait, Baréin, Irán, Irak, Emiratos Árabes Unidos, Omán, Yemen, Siria, Líbano, Territorios Ocupados de Palestina, Israel, Corea del Sur, China, Tailandia. En 
cualquier caso, consultar las actualizaciones de la OMS en el siguiente enlace: http://www.who.int/csr/disease/ coronavirus_infections/en/index.html.

- Los pacientes no son contagiosos durante el periodo de incubación. El paciente sintomático puede eliminar virus después de la resolución de los síntomas, aunque la duración del periodo de infectividad es desconocida.

- La mayoría de los pacientes presentan una clínica de neumonía y una proporción importante han desarrollado fallo renal en el curso de la enfermedad. Sin embargo, pueden formar parte del espectro clínico de la infección cuadros más leves y cuadros en los que la presentación clínica no es exclusivamente respiratoria. Un tercio de los pacientes han presentado síntomas gastrointestinales, incluido diarrea. Además, los pacientes con comorbilidades e inmunosupresión pueden tener un riesgo aumentado de infección y pueden presentar un cuadro clínico más grave o atípico. Se han notificado coinfecciones con otros virus respiratorios como el virus de la gripe o rinovirus

3. En el momento de la sospecha estos individuos deberán separarse de otros sujetos, se les colocará una mascarilla quirúrgica y serán conducidos de forma inmediata a una zona de aislamiento. El personal que les acompañe hasta la zona de aislamiento llevará al menos también mascarilla quirúrgica y guantes de protección. Es fundamental determinar en cada Unidad en TN o ZO un lugar adecuado para alojar a cualquier sospechoso (confirmado o no) separado del resto del personal.

El Jefe de Sanidad deberá notificar con carácter urgente la situación a:

- En Zona de Operaciones al Mando de Operaciones.

- En territorio nacional a:

Instituto de Medicina Preventiva de la Defensa (IMPDEF)

Teléfono de Oficial de Servicio de IMPDEF (24h): +34 679475899

Teléfono de contacto con IMPDEF (en horario laboral): Red civil: +34 914222349 Red militar: 8212349

Correo electrónico: impdef@mde.es

4. Los casos en investigación y confirmados que requieran tratamiento deberían ser ubicados directamente en habitaciones individuales con baño incluido, restringiéndose al máximo el acceso a esta zona, tanto para el personal sanitario como no sanitario.

- El personal sanitario que atienda a personas en investigación para la posible infección por nuevo coronavirus o las personas que entren en la habitación de aislamiento (p. ej familiares, personal de limpieza...) deben utilizar Equipos de Protección Individual corporal y respiratoria (Tabla 1$)^{13,14}$.

- Los procedimientos médicos, especialmente aquellos que generen aerosoles y cualquier otro tipo de procedimiento sobre la vía aérea, como la intubación traqueal, el lavado bronco-alveolar, ventilación manual requieren medidas de protección especiales. Durante la realización del procedimiento, se deberán reducir al mínimo el número de personas en la habitación y todos deben llevar EPI adecuado.

- Es importante tener un listado de todo el personal que atiende a casos sospechosos o confirmados de infección por nuevo coronavirus. Este personal sanitario debe autovigilar cualquier síntoma respiratorio en los 14 días posteriores a la última exposición a un caso confirmado para informar inmediatamente al personal sanitario y poder realizar el diagnóstico oportuno y proceder a su aislamiento si enfermara.

5. Cuando sea necesario realizar el transporte del paciente se realizará en una ambulancia especialmente preparada, con la cabina del conductor físicamente separada del área de transporte del paciente. El personal que intervenga en el transporte deberá ser informado previamente y deberá utilizar equipo de protección individual adecuado (ver en los puntos anteriores). Una vez finalizado el transporte se procederá a la desinfección del vehículo y a la gestión de los residuos producidos ${ }^{15}$.

6. Para el manejo de muestras biopatológicas se extremarán las medidas de precaución. En caso de tener que enviar muestras biopatológicas para diagnóstico se gestionaran al procedimiento de envío de muestras de categoría B (UN 3373 Biocontenedor de Seguridad 6.2). Todas las muestras recogidas para investigación por el laboratorio deben ser tratadas como potencialmente infecciosas, y el personal que recogen muestras clínicas deben llevar el Equipo de Protección Individual adecuado para minimizar la posibilidad de exposición a los patógenos. Para la toma de muestras se deben seguir las indicaciones que se describen para los procedimientos que pueden generar de aerosoles $^{16-18}$.

7. Gestión de residuos: Los residuos generados por la atención y aislamiento de los enfermos se consideran residuos de Clase III o como residuos Biosanitarios Especiales (la incertidumbre existente en este momento con respecto al modo de transmisión obliga a ser más conservador y considerarlo como residuo Biosanitario Especial del Grupo 3, similar a la tuberculosis) ${ }^{19,20}$.

- Estos materiales se han de acumular en envases exclusivos separados de cualquier otro tipo de residuo generado. Esta acumulación se ha de realizar tan pronto como sea posible.

- Se recogerán en contenedores de un sólo uso, de polietileno o de poliestireno, de manera que permitan la incineración completa, que sean resistentes a los agentes químicos y a los materiales perforantes y que dispongan de cierre hermético especial, con bolsa plástica en su interior. (Ley 22/2011, de 28 de julio, de residuos y suelos contaminados),

- El contenedor será cerrado cuando la bolsa esté ocupada al $80 \%$.

- El contenedor cerrado deberá ser descontaminado con la solución elegida, antes de salir de la zona sucia 
- El material cortante y punzante se desechará en un contenedor rígido.

- Los materiales que no sean desechables y no sean susceptibles de esterilización mediante autoclavado (tensiómetro, fonendo...) permanecerán en la zona de aislamiento hasta su posterior desinfección con solución desinfectante.

- Para asegurar un sistema seguro de trabajo se deben seguir los protocolos de descontaminación, mantenimiento y eliminación de residuos utilizados habitualmente para otro tipo de microorganismos con el riesgo de propagación y mecanismo de transmisión similar.

8. Gestión de residuos en Zona de Operaciones. En caso de no existir un gestor de residuos autorizado se procederá a su incineración con medios propios de acuerdo a lo marcado en los procedimientos de la Organización Mundial de la Salud. Para lo cual el personal dedicado a esta tarea utilizará el $\mathrm{EPI}^{21-24}$.

- Todos los residuos generados serán introducidos en bolsas rojas de 60 litros de capacidad y sólo se llenaran hasta el $80 \%$ de su capacidad, procediendo a su cierre mediante el uso de bridas.

- Los contenedores de objetos punzantes y cortantes serán desechados en doble bolsa, considerándose el recipiente como primer contenedor.

- Para desinfectar se utilizará una solución de monopersulfato, sulfonato y ácido sulfámico al $1 \%$ (1:100) o una solución de hipoclorito sódico o cálcico al 0,35-0,50\%.

- Una vez recogidas las bolsas de residuos generados de la zona de almacenamiento se procederá a la incineración individualizada, para luego ser gestionados como el resto de los residuos sólidos urbanos establecido en el despliegue. decisión de levantar las precauciones de aislamiento en los pacientes hospitalizados. El fin del aislamiento se realizará cuando se obtengan dos resultados negativos en muestras respiratorias tomadas con al menos un día de diferencia.

\section{Implementar las medidas de cuarentena y aislamiento necesarias}

En función de las condiciones logísticas y operativas presentes, los servicios sanitarios considerarán o no la necesidad de adoptar medidas de aislamiento, así como la restricción de movimientos, para lo cual ${ }^{28-33}$ :

1. Asesorarán al jefe de la unidad para el establecimiento de un plan de contingencia, progresivo en función de las necesidades, al objeto de aislar a los casos sospechosos de otros pacientes, del personal y de las visitas.

2. Se garantizará la asistencia sanitaria en óptimas condiciones:

- Asegurando el número suficiente de camas para el personal en observación y los contactos:

- Se restringirá el acceso a la zona de cuarentena y aislamiento al personal estrictamente necesario, estableciéndose un registro de entradas y salidas al objeto de establecer los posibles contactos.

- El personal en aislamiento deberá disponer de áreas exclusivas de ablución.

- Se procurará que el menaje utilizado por el personal sea de un solo uso, gestionándose como residuo.

- Se realizará una adecuada gestión de residuos, así como se establecerá un programa de limpieza y desinfección.

- Se establecerá un registro de control de temperatura dos veces al día para todo el personal que entra y permanece en el área de cuarentena y aislamiento.
9. Se debe realizar la limpieza y desinfección de las superficies con las que ha estado en contacto el enfermo ${ }^{25}$. La limpieza y desinfección se realizará con un desinfectante eficaz (tipo alcohol, amonio cuaternario o con una solución de hipoclorito sódico (dilución 1:50 de una lejía con concentración 40-50 gr/litro preparada recientemente). Este virus se inactiva tras el contacto 5 minutos con desinfectantes normales como la lejía doméstica ${ }^{26,27}$. El personal de limpieza utilizará equipo de protección individual adecuado. Siempre que exista riesgo de crear aerosoles, se usará mascarilla FFP3.

10. La duración de la infectividad en un paciente del nuevo coronavirus es desconocida. Los pacientes muy graves pueden difundir el virus durante largos periodos de tiempo y los test de detección viral deberían ayudar a tomar la

\begin{tabular}{|c|c|c|c|}
\hline \multirow{2}{*}{$\begin{array}{l}\text { Equipos de } \\
\text { Protección }\end{array}$} & \multirow[b]{2}{*}{ Protección Corporal } & \multicolumn{2}{|c|}{ Protección respiratoria } \\
\hline & & $\begin{array}{l}\text { Atención al paciente } \\
\text { sin generar aerosoles }\end{array}$ & $\begin{array}{c}\text { Procedimientos } \\
\text { médicos que generen } \\
\text { aerosoles }\end{array}$ \\
\hline $\begin{array}{c}\text { Personal } \\
\text { sanitario/no } \\
\text { sanitario en } \\
\text { contacto con } \\
\text { enfermos GRAVES* }\end{array}$ & $\begin{array}{c}\text { Trajes Categoría III (Tipo } 4 \\
\text { o } 3 \text { ) } \\
\text { Guantes de Nitrilo/latex } \\
\text { Calzas } \\
\text { Pantalla facial/Gafas } \\
\text { antisalpicaduras } \\
\text { Gorro }\end{array}$ & $\begin{array}{l}\text { Mascarillas de } \\
\text { protección } \\
\text { respiratoria tipo } \\
\text { FFP2 }\end{array}$ & $\begin{array}{l}\text { Mascarillas de } \\
\text { protección } \\
\text { respiratoria tipo } \\
\text { FFP3 }\end{array}$ \\
\hline $\begin{array}{c}\text { Personal } \\
\text { sanitario/no } \\
\text { sanitario en } \\
\text { contacto con } \\
\text { enfermos NO } \\
\text { GRAVES }\end{array}$ & $\begin{array}{c}\text { Bata quirúrgica completa } \\
\text { Guantes de Nitrilo/ látex } \\
\text { Calzas } \\
\text { Pantalla facial/Gafas } \\
\text { antisalpicaduras } \\
\text { Gorro }\end{array}$ & \multicolumn{2}{|c|}{$\begin{array}{c}\text { Mascarillas de protección respiratoria tipo } \\
\text { FFP2 }\end{array}$} \\
\hline Enfermos & & \multicolumn{2}{|c|}{ Mascarilla quirúrgica } \\
\hline
\end{tabular}

*Enfermos GRAVES: enfermedad febril respiratoria aguda, con evidencia clínica, radiológica o histopatológica de enfermedad pulmonar parenquimatosa (ej. neumonía o síndrome de distrés respiratorio agudo) 
3. El área de aislamiento debe tener una buena ventilación. Siempre que sea posible el sistema de climatización debe ser independiente del sistema central.

4. El personal sanitario y no sanitario que acceda a la zona de cuarentena y aislamiento deberá adoptar el adecuado nivel de protección individual.

- Los contactos deberán llevar mascarilla desde el momento en que pasan a la zona de cuarentena.

- Los casos sospechosos, en función de su situación clínica, deberá portar mascarilla a juicio clínico.

\section{BIBLIOGRAFÍA}

1. World Health Organization. Middle East respiratory syndrome coronavirus (MERS-CoV). (accedido 03/07/15). Disponible en: http://www.who.int/emergencies/mers-cov/en/

2. Command \& Control Center. Ministry of Health Saudi Arabia. Statistics Coronavirus (MERS-CoV). 2015 July 2 (acedido 03/07/15). Disponible en: http://www.moh.gov.sa/en/CCC/PressReleases/Pages/default.aspx

3. World Health Organization. IHR Emergency Committee concerning Middle East respiratory syndrome coronavirus (MERS-CoV). 2013 July 17 (acedido 03/07/15). Disponible en: http://www.whoint7ihr7ihr_ec_2013/en/index.html

4. World Health Organization. WHO statement on the ninth meeting of the IHR Emergency Committee regarding MERS-CoV. WHO Statement. 17 June 2015 (acedido 03/07/15). Disponible en: http://www.who.int/mediacentre/news/statements/2015/ihr-ec-mers/en/

5. Ponencia de Alertas de Salud Pública y Planes de Preparación y Respuesta. Procedimiento de actuación frente a casos de infección por el nuevo coronavirus (MERS-CoV) Centro de Coordinación de Alertas y Emergencias Sanitarias Secretaria General de Sanidad y Consumo. Dirección General de Salud Pública, Calidad e Innovación. Aprobado por la Comisión de Salud Pública el 11.02.2015. Versión actualizada a 11 de febrero de 2015.

6. Centro de Coordinación de Alertas y Emergencias Sanitarias. Informe de situación y evaluación del riesgo del MERs-CoV en relación al brote actual en Corea del Sur. Secretaria General de Sanidad y Consumo. Dirección General de Salud Pública, Calidad e Innovación. 26/junio/2015.

7. Chu DK, Poon LL, Gomaa MM, Shehata MM, Perera RA, et al. MERS coronaviruses in dromedary camels, Egypt. EID 2014;20(6):1049-1053.

8. Memish ZA, Cotten M, Meyer B, Watson SJ, Alsahafi AJ, et al. Human infection with MERS coronavirus after exposure to infected camels, Saudi Arabia, 2013. EID 2014;20(6):1012-1015.

9. Reusken CB, Farag EA, Jonges M, Godeke GJ, El-Sayed AM, et al. Middle East respiratory syndrome coronavirus (MERS-CoV) RNA and neutralising antibodies in milk collected according to local customs from dromedary camels, Qatar, April 2014. Euro Surveill. 2014;19(23):pii=20829. (acedido 03/07/15). Disponible en: http://www.eurosurveillance.org/ViewArticle. aspx?ArticleId=20829

10. World Health Organization. Infection prevention and control of epidemics and pandemic-prone acute respiratory infections in health care. April 2014 (acedido 03/07/15). Disponible en: http://www.who.int/csr/bioriskreduction/ infection_control/publication/en/

11. World Health Organization. Interim surveillance recommendations for human infection with Middle East respiratory syndrome coronavirus. 2014 Jul 14 (acedido 03/07/15). Disponible en: http://www.who.int/csr/disease/ coronavirus_infections/InterimRevisedSurveillanceRecommendations_ nCoVinfection_14July2014.pdf

12. World Health Organization. Laboratory Testing for Middle East Respiratory Syndrome Coronavirus. Interim recommendations (revised) $2014 \mathrm{Sep}$ 1. (acedido 03/07/15). Disponible en: http://www.who.int/csr/disease/coronavirus_infections/WHO_interim_recommendations_lab_detection_MERSCoV_092014.pdf

13. Servicio de Prevención de Riesgos Laborales del Servicio Riojano de Salud. Protección Respiratoria: Mascarillas Quirúrgicas y Mascarillas de Protec- ción. Gobierno de La Rioja (accedido 23/06/15) Disponible en: http://www. riojasalud.es/rrhh-files/rrhh/proteccion-respiratoria-rev-3175.pdf

14. Dirección General de Salud Pública. Anexo-II Medidas de Control de la infección. Plan Nacional de Preparación y Respuesta ante una Pandemia de Gripe. Subcomité de Respuesta a la Emergencia. Ministerio de Sanidad y Consumo Junio 2006. (accedido 23/06/15). Disponible en: http://www.msssi.gob.es/ciudadanos/enfLesiones/enfTransmisibles/docs/anexoII_junio2006.pdf

15. Inspección General de Sanidad de la Defensa. Prevención y control de la Enfermedad por el Virus Ébola en las FAS. Instrucción Técnica n. 05, de 5 de noviembre de 2014

16. Instituto de Salud Pública de Chile. Normativa Técnica para el Transporte de Sustancias Infecciosas a Nivel Nacional hacia el Instituto de Salud Pública (ISP) Gobierno de Chile. 2008

17. Organización Mundial de la Salud. Guia sobre la reglamentación relativa al Transporte de Sustancias infecciosas 2007-2008. Aplicable a partir del 1 de enero de 2007

18. Guardino Solá Xavier NTP 628: Riesgo biológico en el transporte de muestras y materiales infecciosos. Instituto Nacional de Seguridad en el Trabajo. Ministerio de Trabajo y Asuntos Sociales. (accedido 23/06/15). Disponible en: http://www.insht.es/InshtWeb/Contenidos/Documentacion/FichasTecnicas/NTP/Ficheros/601a700/ntp_628.pdf

19. Martí Solé María del Carmen, Alonso Espadalé Rosa $M^{a}$ NTP 372: Tratamiento de residuos sanitarios. Instituto Nacional de Seguridad en el Trabajo. Ministerio de Trabajo y Asuntos Sociales. (accedido 23/06/15). Disponible en: http://www.ucm.es/data/cont/docs/3-2013-02-18-4-TRATAMIENTO $\% 20$ DE\%20RESIDUOS\%20SANITARIOS.pdf

20. Comunidad de Madrid. Residuos con características especiales. (accedido 05/07/15). Disponible en: http://www.madrid.org/cs/Satellite?c=CM_InfPractica_FA\&cid $=1114179113325 \&$ pagename $=$ ComunidadMadrid $/$ Estructura\&pv=1114179122239\#2

21. United States of America. Environmental Guidebook for Military Operations. March 2008.

22. Hyman Mark, Turner Brandon, Carpintero Ainhoa. Guía para la Elaboración de Estrategias Nacionales de Gestión de Residuos. Avanzar desde los Desafíos hacia las Oportunidades. Programa de las Naciones Unidas para el Medio Ambiente. 2013.

23. Instituto de Medicina Preventiva de la Defensa. Recomendaciones Higiénico-Sanitarias en Operaciones y Ejercicios. $5^{\circ}$ Ed. 2013.

24. Área de Preparativos para Situaciones de Emergencia y Socorro en Casos de Desastre Centro Panamericano de Ingeniería Sanitaria y Ciencias del Ambiente. Gestión de Residuos sólidos en situaciones de desastre. Organización Panamericana de la Salud 2003.

25. Van Doremalen N, Bushmaker T, Munster VJ. Stability of Middle East respiratory syndrome coronavirus (MERS-CoV) under different environmental conditions. Euro Surveill. 2013;18(38):pii=20590. accedido 05/07/15) Disponible en: http://www.eurosurveillance.org/ViewArticle.aspx?ArticleId=20590

26. G. McDonnell \& A. Denver Russel. Antiseptics and Disinfection. Activity, Action and Resistance. Clin Microb Rev 1999; 12(1):147-179

27. Rutala William A., Weber David J., and the Healthcare Infection Control Practices Advisory Committee (HICPAC) Guideline for Disinfection and Sterilization in Healthcare Facilities, 2008. Centers for Diseases and Control.

28. NATO Standardization Agency. STANAG 2278: Medical Advice to Commanders on Restriction of Movement of BW Exposed Troops.

29. J R Army Med Corp. Restriction Of MovementJ R Army Med Corps 2003 149: 224

30. California Department of Health Services - Centers for Diseases Control and Prevention. Isolation and Quarantine - Spanish - October 2006 (accedido 05/07/15) Disponible en: http://www.cdph.ca.gov/HealthInfo/environhealth/btagents/Documents/SP_IsoQuar.pdf

31. Instituto Social de la Marina. Prevención de enfermedades crónicas y contagiosas Capítulo 11. Bloque IV. Prevención, higiene y muerte en el mar. Guía Sanitaria Marítima (accedido 05/07/15). Disponible en: http://www.seg-social.es/ism/gsanitaria_es/ilustr_capitulo11/cap11_2_aislamiento.htm

32. Centers for Disease Control and Prevention. CDC - Interim Guidance for Health Professionals. Evaluation and Management of close contacts. 2014 (acedido 03/07/15). Disponible en: http://www.cdc.gov/coronavirus/mers/ interim-guidance.html

33. Organización Mundial de la Salud. Reglamento Sanitario Internacional (2005) Segunda Edición Ginebra 2008. 